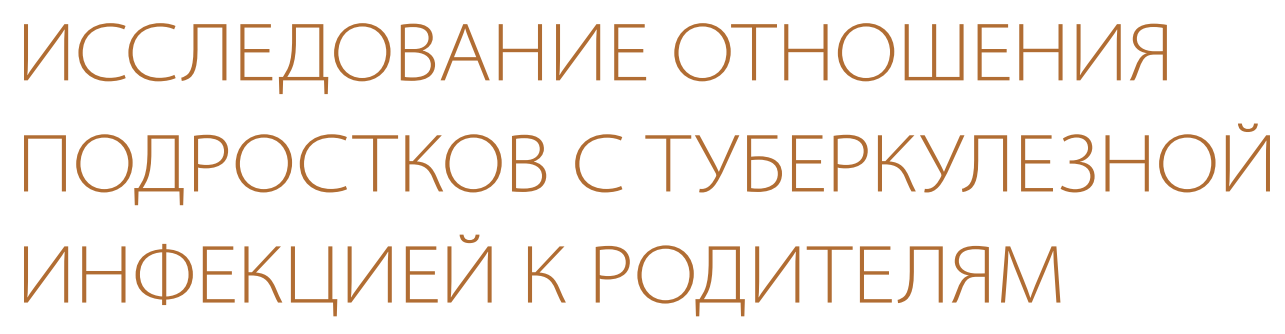

\title{
STUDY OF THE ATTITUDE OF ADOLESCENTS WITH TUBERCULAR INFECTION TO THEIR PARENTS
}

\section{Захарова Елена Владимировна}

Заведующий кафедрой общей психологии и социальной работы, федеральное государственное бюджетное образовательное учреждение высшего образования «Самарский государственный медицинский университет» Министерства здравоохранения Российской Федерации, кандидат медицинских наук, доцент E-mail: proscha1088@mail.ru

Аннотация. Представленная статья посвящена изучению отношений подростков с туберкулезной инфекцией к родителям. Известно, что туберкулез относится к тяжелым соматическим инфекционным заболеваниям. Его лечение осуществляется в условиях стационара и амбулаторно длительное время. Прогноз течения и излечения заболевания не всегда ясен и предсказуем. Тяжесть заболевания, побочное действие лекарств, изменение условий и качества жизни, нарушение социальных контактов, неопределенность ближайшего и отдаленного прогнозов здоровья, нарушение

\section{Zakharova Elena V.}

Head of the Department of General

Psychology and Social Work, Samara State

Medical University, Doctor of Medicine,

Associate Professor

E-mail: proscha1088@mail.ru

Abstract. The presented article is devoted to the study of the relationship of adolescents with tubercular infection to their parents. Tuberculosis is known to be a serious somatic infectious disease. Its treatment is carried out in a hospital and outpatiently for a long time. The prognosis of the course and cure of the disease is not always clear and predictable. The severity of the disease, side effects of drugs, changes in conditions and quality of life, disruption of social contacts, uncertainty of near and distant health prognoses, disruption of family relationships, social and

(C) Захарова Е. В., 2020 
внутрисемейных отношений, социальное и материальное неблагополучие существенно влияют на отношение к болезни, лечению и излечению от туберкулеза. Подростковый возраст является одним из самых сложных периодов в жизни каждого человека. Заболевание оказывает заметное влияние на взросление подростка, его представление о будущем. Поддержка родителей особенно важна для молодых людей, вынужденных длительно лечиться, осознающих тяжесть своего заболевания, его социальную опасность. Отношения с родителями играют важную роль в адаптации к заболеванию, формированию приверженности лечению. Однако зачастую родители сами становятся источником заражения своего ребенка, формирования у него множественной лекарственной устойчивости. Неправильное воспитание, неадекватное отношение к болезни ребенка и его лечению приводят к нарушению лечебно-диагностического и лечебнореабилитационного процессов, направленных на лечение туберкулеза.

Ключевые слова: туберкулезная инфекция, подростки, социально-психологическая адаптация, отношение к болезни, стиль воспитания, детско-родительские отношения. material distress significantly affect attitudes toward the disease, treatment and cure for tuberculosis. Adolescence is one of the most difficult periods in every person's life. The disease has a significant effect on the adolescent's growing up, their ideas of future. Parental support is especially important for young people who have to be treated for a long time, who are aware of the severity of their disease, its social danger. Relations with parents play an important role in adapting to the disease, in forming adherence to treatment. However, often parents themselves become a source of infection for their child, the formation of multiple drug resistance. Improper upbringing, inadequate attitude to the child's disease and its treatment lead to disruption of the medical-diagnostic and medical-rehabilitation processes aimed at treating tuberculosis.

Keywords: tubercular infection, adolescents, socio-psychological adaptation, attitude to the disease, upbringing pattern, parent-child relationships.

Проблема заболеваемости туберкулезом детей и взрослых во всем мире остается значимой и актуальной. Снижение заболеваемости туберкулезом сопровождается увеличением количества пациентов (особенно среди детей и подростков) с множественной лекарственной устойчивостью. Существующие методы диагностики и лечения повышают эффективность лечения и излечения от туберкулеза, однако во множестве стран мира и регионов России заболеваемость и смертность от туберкулеза остается высокой.

Несмотря на предпринимаемые меры, эпидемическая ситуация в целом остается напряженной, возрастает число прогрессирующих и тяжелых форм туберкулеза, а также расширение спектра лекарственной устойчивости, особенно у детей и подростков.

Отношения с родителями важны для человека в любом возрасте. Однако для подростков, оказавшихся в ситуации тяжелого соматического заболевания, взаимоотношения в семье, с родителями приобретают особое значение, влияя на социально-психологическую 
адаптацию ребенка, определяя его отношение к болезни и лечению, оказывая влияние на формирование приверженности лечению.

С помощью методики «Поведение родителей и отношение подростков к ним» проведено исследование отношения подростков с туберкулезной инфекцией лишь к матери [1].

Это связано с тем, что много респондентов воспитываются в неполных семьях (родители находятся в разводе или отец умер, в том числе от туберкулеза) или отец, находясь в семье, не принимает участия в воспитании детей или находится в местах лишения свободы. То есть воспитанием подростков в большинстве случаев занимается мать.

Эмпирическое исследование проводилось с 2000 по 2017 г. Обследование испытуемых осуществлялось строго в индивидуальной форме. Психодиагностические обследование проводилось с информированного согласия пациентов и/или родителей (официальных представителей) несовершеннолетних испытуемых.

Экспериментальную группу составили 150 человек: 66 мальчиков и 84 девочки в возрасте 13-18 лет - пациенты детского туберкулезного стационарного отделения противотуберкулезного диспансера г.о. Самара, а также подростки, находящиеся на амбулаторном лечении, но ранее проходившие лечение в стационаре.

Критерии включения в экспериментальную группу: информированное согласие на участие в исследовании, наличие диагноза туберкулез внутригрудных лимфатических узлов, первичный туберкулезный комплекс, очаговый туберкулез, инфильтративный туберкулез, туберкулезный плеврит. Половина всех опрошенных подростков проживают в неполных семьях, 3\% респондентов проживают в приемных семьях, 6\% - с опекунами. 16\% респондентов из многодетных семей.

Большая часть подростков экспериментальной группы проживают в городе Самара. 36\% респондентов постоянно проживают в крупных городах и мелких населенных пунктах Самарской области. 64\% всех респондентов-подростков экспериментальной группы имели контакт с близким родственником, проживающим совместно. Еще 16\% контактировали с родственниками, не проживающими на одной жилплощади с испытуемыми. У 27\% подростков экспериментальной группы один из родителей (в большинстве случаев отец) умер от туберкулеза.

Контрольная группа идентична экспериментальной по численности и половозрастному составу. В нее вошли подростки общеобразовательных школ г. Самара, условно здоровые.

Для сопоставления частоты встречаемости интересующего нас показателя использован критерий углового преобразования Фишера. Для сравнения степени выраженности социальной, эмоциональной, поведенческой и общей комплаентности у подростков с туберкулезной инфекцией в зависимости от пола и возраста использовали U-критерий Манна - Уитни.

Особенности восприятия и понимания подростками воспитательной практики матери описываются с помощью 5 шкал и их комбинаций, а также с помощью 2 факторов. В табл. 1 представлены результаты сравнения шкальных оценок, полученных в группе подростков 13-15 лет с туберкулезной инфекцией и в контрольной группе.

В табл. 2 представлены результаты сравнения шкальных оценок, полученных в группе подростков 16-18 лет с туберкулезной инфекцией и в контрольной группе. 
Таблица 1

Шкальные оценки, отражающие отношение к родителям (матери) подростков 13-15 лет с туберкулезной инфекцией и в контрольной группе (баллы)

\begin{tabular}{|c|c|c|c|c|c|c|c|c|c|}
\hline & 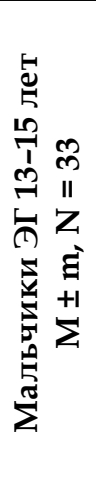 & 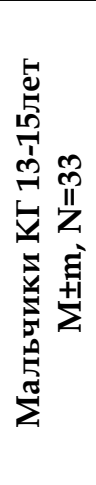 & 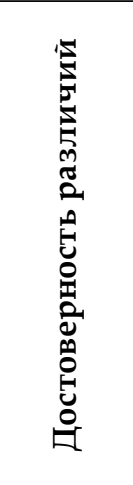 & 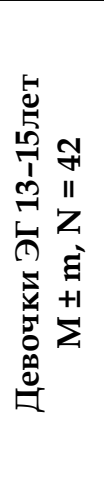 & 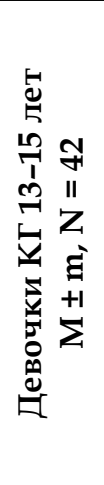 & 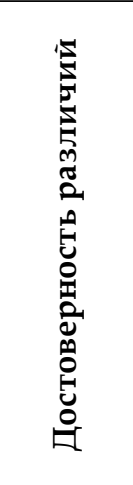 & 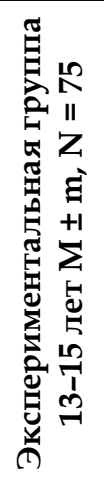 & 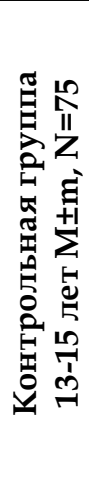 & 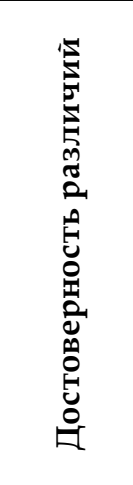 \\
\hline $\begin{array}{l}\text { Шкала позитивного } \\
\text { интереса }\end{array}$ & 4,0 & 3,2 & $\mathrm{p} \leq 0,05$ & 3,3 & 3,0 & - & 3,6 & 3,1 & $\mathrm{p} \leq 0,05$ \\
\hline Шкала директивности & 3,4 & 3,3 & - & 2,8 & 2,9 & - & 3,1 & 3,1 & - \\
\hline Шкала враждебности & 4,3 & 3,0 & $p \leq 0,05$ & 4,3 & 2,8 & $p \leq 0,05$ & 4,3 & 2,9 & $p \leq 0,05$ \\
\hline Шкала автономности & 3,9 & 3,5 & - & 3,4 & 3,3 & - & 3,6 & 3,4 & - \\
\hline $\begin{array}{l}\text { Шкала непоследова- } \\
\text { тельности }\end{array}$ & 2,9 & 2,4 & - & 3,8 & 2,8 & $\mathrm{p} \leq 0,05$ & 3,4 & 2,6 & $\mathrm{p} \leq 0,05$ \\
\hline Фактор близости & 4,0 & 3,1 & $\mathrm{p} \leq 0,05$ & 3,9 & 2,9 & $p \leq 0,05$ & 3,9 & 3,0 & $p \leq 0,05$ \\
\hline Фактор критики & 3,5 & 3,4 & - & 2,8 & 3,1 & - & 3,1 & 3,3 & - \\
\hline
\end{tabular}

Таблица 2

Шкальные оценки, отражающие отношение к родителям (матери) подростков 16-18 лет с туберкулезной инфекцией и в контрольной группе (баллы)

\begin{tabular}{|c|c|c|c|c|c|c|c|c|c|}
\hline & 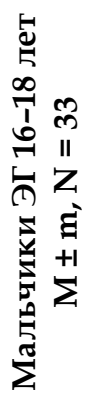 & 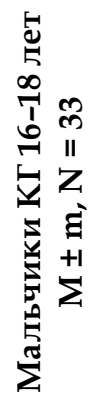 & 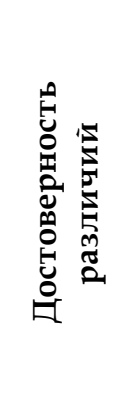 & 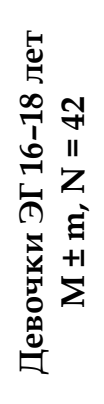 & 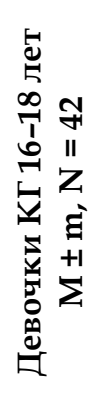 & 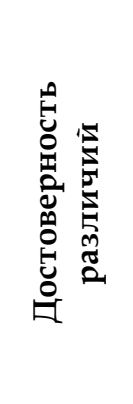 & 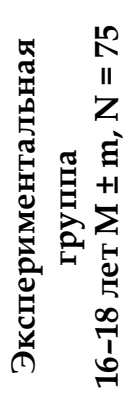 & 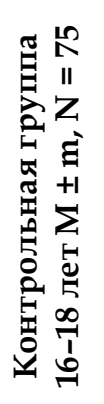 & 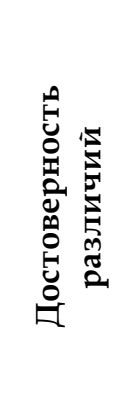 \\
\hline $\begin{array}{l}\text { Шкала позитивного } \\
\text { интереса }\end{array}$ & 4,4 & 3,4 & $\mathrm{p} \leq 0,05$ & 4,4 & 3,2 & $\mathrm{p} \leq 0,05$ & 4,4 & 3,3 & $\mathrm{p} \leq 0,05$ \\
\hline Шкала директивности & 3,4 & 3,1 & - & 3,1 & 3,2 & - & 3,2 & 3,1 & - \\
\hline Шкала враждебности & 4,3 & 2,9 & $\mathrm{p} \leq 0,05$ & 4,4 & 2,7 & $\mathrm{p} \leq 0,05$ & 4,3 & 2,8 & $p \leq 0,05$ \\
\hline Шкала автономности & 3,4 & 3,3 & - & 3,6 & 3,6 & - & 3,5 & 3,5 & - \\
\hline $\begin{array}{l}\text { Шкала непоследова- } \\
\text { тельности }\end{array}$ & 2,0 & 2,3 & - & 2,8 & 2,2 & - & 2,4 & 2,2 & - \\
\hline Фактор близости & 4,2 & 3,2 & $\mathrm{p} \leq 0,05$ & 4,1 & 2,9 & $\mathrm{p} \leq 0,05$ & 4,2 & 3,1 & $\mathrm{p} \leq 0,05$ \\
\hline Фактор критики & 3,2 & 3,2 & - & 3,0 & 3,4 & - & 3,1 & 3,3 & - \\
\hline
\end{tabular}


Анализ полученных данных позволяет дать характеристику отношений подростков с матерями. Так, в экспериментальной группе мальчиков 13-15 лет отмечается повышение значения по шкале позитивного интереса $(4,0)$. Психологическое принятие матери они видят в относительно критическом подходе к ним. Респонденты указанной группы склонны соглашаться с мнением матери. При этом они отрицают ее властность и подозрительность. Подростки стремятся к сверхопеке взрослого человека, проявляющего самостоятельность и искренний интерес к жизни ребенка.

В экспериментальной группе юношей и девушек 16-18 лет также отмечается повышение значения шкалы позитивного интереса (4,3 и 4,4 балла соответственно). Респонденты принимают мать, несмотря на ее критику, властность и подозрительность. Эти качества испытуемые указанной группы стремятся отвергать и объясняют проявляемым интересом к жизни своих детей.

Среднее шкальное значение шкалы враждебности в экспериментальной группе подростков в возрасте 13-15 лет и в возрасте 16-18 лет равно 4,3. Это наиболее отчетливо выраженная характеристика отношения подростков к матери. Так, мальчики данной группы описывают отношения с матерью как агрессивные, отличающиеся чрезмерной строгостью. Поведение матери ориентировано преимущественно на себя, она стремится самоутвердиться, у нее выражено самолюбие, собственная значимость. При этом ребенок воспринимается как соперник, который мешает и которого надо подавить. Поведение таких матерей характеризуется манипулятивностью в отношении детей. Отмечается эмоциональная холодность, сдержанность, стремление следовать общепринятым нормам и правилам поведения. Однако часто матери демонстрируют враждебное отношение к сыну, проявляющееся в выраженной подозрительности, склонности к чрезмерной критике в его адрес, стремлении унизить его в глазах окружающих. При этом на вербальном уровне матери демонстрируют позитивную активность и ответственность за судьбу сына.

Девушки экспериментальной группы описывают матерей как подозрительных, дистанцированных по отношению к членам семьи, отказывающихся соблюдать социальные нормы, отгораживающихся от окружающих, стремящихся возвысить себя над остальными.

В группе мальчиков 13-15 лет шкала автономности имеет тенденцию к повышению $(3,9)$. Мать воспринимается сыном как диктатор, испытывающий упоение властью и стремящийся к удовлетворению своих амбиций. Такие матери стремятся подчинить себе всех членов семьи, особенно сыновей. При этом ребенок не воспринимается такой матерью как самостоятельная личность. В группе 16-18-летних испытуемых среднее значение по данной шкале составляет 3,5 балла. При этом у юношей 16-18 лет значение показателя несколько ниже $(3,3)$, чем у мальчиков 13-15 лет. А у девушек 16-18 лет выше $(3,6)$, чем у девочек 13-15 лет $(3,4)$.

В группе девочек 13-15 лет отмечается тенденция к повышению значения шкалы непоследовательности $(3,8)$. Девушки отмечают, что по отношению к ним матери непоследовательны, склонны резко менять стиль воспитания от очень строгого к попустительскому и наоборот. Периоды эмоционального принятия резко сменяются эмоциональным отвержением независимо от поступка ребенка. В группе девушек 16-18 лет данный показатель ниже и составляет 2,8 балла. Отмечается тенденция к снижению значения по шкале непоследовательности в группе юношей 16-18 лет (1,9) по сравнению с группой мальчиков 13-15 лет $(2,9)$. 
Это характеризует отношение матери к сыну как относительно устойчивое, без значимых колебаний, не зависящее от информативной значимости происходящих событий.

Остальные шкалы имеют средние значения в группах испытуемых, и их интерпретация имеет значение в индивидуальной психодиагностической, психокоррекционной и консультативной работе.

На основании полученных шкальных оценок были вычислены фрактор близости (отношение позитивного интереса к враждебности) и фактор критики (отношение директивности к автономности). Оказалось, что в группе испытуемых 16-18 лет фактор близости несколько выше, чем в группе 13-15-летних испытуемых (4,2 и 3,9 балла соответственно). Данный показатель характеризует степень проявления теплых чувств и принятия своего ребенка. Однако анализ ответов испытуемых, дополнительная беседа с ними позволяют говорить о том, что для респондентов такое поведение матерей крайне желательно и предпочтительно, однако в большинстве случаев не проявляется. Фактор критики характеризует степень заинтересованности и тотального контроля родителя в отношении своего ребенка. В обеих группах испытуемых значение данного фактора равно 3,1 балла, однако у мальчиков 13-15 лет составляет 3,5 балла, что может свидетельствовать о несколько более выраженном контроле за ними со стороны матерей.

Сочетание повышенных значений по шкалам позитивного интереса и враждебности в группе мальчиков 13-15 лет позволяет ожидать увеличение вероятности развития неврозоподобных расстройств и формирования отклоняющегося поведения испытуемых с последующей нарастающей социально-психологической дезадаптацией.

Повышение значений шкал враждебности и непоследовательности в группе девочек 13-15 лет позволяет говорить о проявляющихся по отношению к испытуемым безразличия, негативных высказываний, демонстрации в их адрес неверия в достижение высоких результатов какой-либо деятельности. Это приводит к отчуждению ребенка по отношению к матери и, как следствие, нарушению социально-психологической адаптации.

В группе респондентов 16-18 лет (и юноши, и девушки) также отмечается сочетание повышенных значений по шкалам позитивного интереса и враждебности, что свидетельствует об увеличении вероятности развития неврозоподобных расстройств и формирования отклоняющегося поведения испытуемых с последующей нарастающей социально-психологической дезадаптацией.

В контрольной группе испытуемых отмечаются статистически значимые отличия выраженности шкал позитивного интереса, враждебности и непоследовательности от показателей в экспериментальной группе. Значения фактора близости также ниже, чем в экспериментальной группе.

Типы нарушения воспитания подростков контрольной группы представлены в табл. 3.

Таким образом, нарушения детско-родительских отношений между подростками и их матерями в экспериментальной группе выражены в большей степени, чем в контрольной. Следовательно, ожидать появления неврозоподобных и психосоматических расстройств и нарушений социально-психологической адаптации в группе подростков с туберкулезной инфекцией приходится чаще, чем у подростков контрольной группы. Это обусловливает необходимость включения в программу психодиагностики и 
психокоррекции детско-родительских отношений на всех этапах лечебно-диагностического и реабилитационного процессов.

В табл. 4 представлены типы нарушения детско-родительских отношений и воспитания в семьях у подростков экспериментальной группы.

У 36\% подростков 13-15 лет и 32\% юношей и девушек 16-18 лет встречается дисгармонично-непоследовательный тип отношений с матерями. Воспитание является дисгармоничным. Подростки дезориентированы в предъявляемых требованиях. Повышается вероятность развития психосоциальной дезадаптации, неврозоподобных нарушений и психосоматических расстройств.

Враждебно-подавляющее отношение матери к подросткам встречается в группе испытуемых 13-15 лет в 20\% случаев, у 16-18-летних респондентов - в 8\% случаев. Это проявляется в жестких и ригидных отношениях между ребенком и матерью, непоследовательности в воспитании, развитии конфронтации со стороны подростков. Это нарушает психическую адаптацию в семье и в социальном окружении, что может приводить к негативным поведенческим расстройствам.

У 24\% подростков 13-15 лет и 40\% респондентов 16-18 лет выявлен отвергающе-отстраненный тип отношения с матерями. Он характеризуется непоследовательностью воспитательных действий, безразличием и попустительством, что может приводить к развитию неврозоподобных расстройств и возникновению отклоняющегося поведения подростков с последующим нарастанием социальной и психической дезадаптации.

В табл. 5 и табл. 6 приведены статистически значимые различия в показателях шкал детско-родительских отношений в зависимости от возраста и пола испытуемых.

Получены статистически значимые различия в оценке испытуемыми экспериментальной группы своих отношений с матерями. Так, в группе подростков 13-15 лет непоследовательность воспитательного процесса отмечается чаще, чем в группе респондентов 16-18 лет.

Таблица 3

Частота встречаемости типов нарушения воспитания и детско-родительских отношений в семьях у подростков контрольной группы (\%)

\begin{tabular}{|c|c|c|c|}
\hline $\begin{array}{c}\text { Возраст/Типы нару- } \\
\text { шения воспитания }\end{array}$ & $\begin{array}{c}\text { Дисгармонично-непосле- } \\
\text { довательное отношение }\end{array}$ & $\begin{array}{c}\text { Враждебно-подав- } \\
\text { лящее отношение }\end{array}$ & $\begin{array}{c}\text { Отвергающе-отстра- } \\
\text { ненное отношение }\end{array}$ \\
\hline $13-15$ лет & 11 & 7 & 8 \\
\hline $16-18$ лет & 9 & 5 & 12 \\
\hline
\end{tabular}

Таблица 4

Частота встречаемости типов нарушения воспитания и детско-родительских отношений в семьях у подростков с туберкулезной инфекцией (\%)

\begin{tabular}{|c|c|c|c|}
\hline $\begin{array}{c}\text { Возраст/Типы нару- } \\
\text { шения воспитания }\end{array}$ & $\begin{array}{c}\text { Дисгармонично-непосле- } \\
\text { довательное отношение }\end{array}$ & $\begin{array}{c}\text { Враждебно-подав- } \\
\text { ляюеее отношение }\end{array}$ & $\begin{array}{c}\text { Отвергающе-отстра- } \\
\text { ненное отношение }\end{array}$ \\
\hline $13-15$ лет & 36 & 20 & 24 \\
\hline $16-18$ лет & 32 & 8 & 40 \\
\hline
\end{tabular}




\section{Анализ взаимосвязи детско-родительских отношений} и возраста подростков с туберкулезной инфекцией

\begin{tabular}{|c|c|c|c|c|c|c|c|}
\hline $\begin{array}{c}\text { Возрастные } \\
\text { подгруппы } \\
\text { 13-15 и 16-18 лет }\end{array}$ & 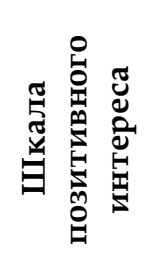 & 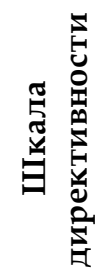 & 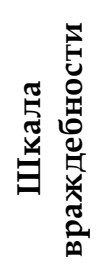 & 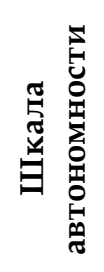 & 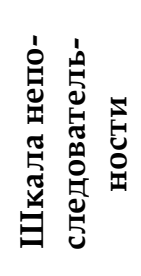 & 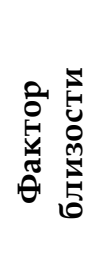 & 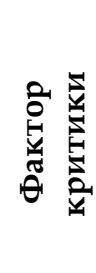 \\
\hline $\begin{array}{l}\text { U-критерий } \\
\text { Манна - Уитни }\end{array}$ & 231,5 & 299,5 & 293,5 & 302,5 & 189,5 & 312,0 & 300,5 \\
\hline $\mathrm{p}$ & 0,1 & 0,8 & 0,7 & 0,8 & 0,0 & 1,0 & 0,8 \\
\hline
\end{tabular}

Таблица 6

Анализ взаимосвязи подростково-родительских отношений и пола подростков с туберкулезной инфекцией

\begin{tabular}{|c|c|c|c|c|c|c|c|}
\hline $\begin{array}{c}\text { Возрастные } \\
\text { подгруппы } \\
\text { 13-15 и 16-18 лет }\end{array}$ & 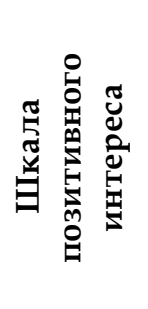 & r & 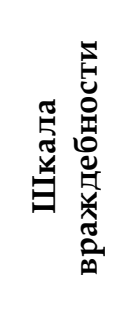 & 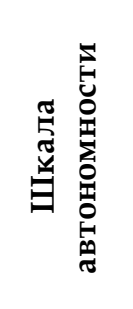 & 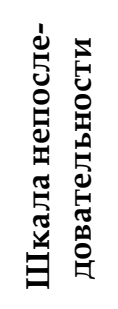 & $\begin{array}{l}5 \\
E \\
0 \\
0 \\
0 \\
0 \\
0 \\
0 \\
0 \\
0 \\
\theta\end{array}$ & 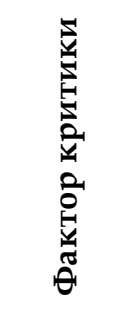 \\
\hline $\begin{array}{l}\text { U-критерий } \\
\text { Манна - Уитни }\end{array}$ & 276,500 & 247,000 & 304,500 & 290,500 & 199,000 & 295,000 & 222,500 \\
\hline $\mathrm{p}$ & 0,472 & 0,219 & 0,938 & 0,723 & 0,028 & 0,783 & 0,064 \\
\hline
\end{tabular}

Девушки экспериментальной группы обеих возрастных подгрупп чаще, чем юноши, отмечали непоследовательность отношений с матерями в процессе воспитания.

Таким образом, в экспериментальной группе отмечается повышение значения по шкале позитивного интереса, враждебности, автономности, непоследовательности, факторов близости и критики. Это свидетельствует о психологическом принятии респондентами своих матерей, склонности соглашаться с ними, отрицании их властности и подозрительности.

Матери воспринимаются подростками как агрессивные, отличающиеся чрезмерной строгостью, склонные к чрезмерной критике, ориентированные преимущественно на себя, стремящиеся к самоутверждению за счет унижения ребенка в глазах окружающих, с выраженным самолюбием и собственной значимостью. В поведении матерей испытуемые отмечают эмоциональную холодность, сдержанность, стремление следовать общепринятым нормам и правилам поведения или, наоборот, отказ соблюдать социальные нормы, отгороженность от окружающих.

При этом указывается, что на вербальном уровне матери демонстрируют позитивную активность и ответственность за судьбу ребенка. Испытуемые экспериментальной группы отмечают, что в отношении с ними матери непоследовательны, склонны резко 
менять стиль воспитания от очень строгого к попустительскому и наоборот. Периоды эмоционального принятия резко сменяются эмоциональным отвержением независимо от поступка ребенка. Отчетливо прослеживается тенденция матерей в отношении с подростками к тотальному контролю их жизни при отсутствии стремления участвовать в ней и давать эмоциональный отклик на происходящее.

По отношению к испытуемым проявляются безразличие, негативные высказывания, демонстрация в их адрес неверия в достижение высоких результатов какой-либо деятельности. Отношения между матерью и подростком характеризуются как жесткие и ригидные. Воспитательный процесс отличается непоследовательностью. Подростки дезориентированы в предъявляемых требованиях, возрастает их конфронтация по отношению не только к матери, но и к социальному окружению в целом. Выявлены дисгармонично-непоследовательный, отвергающе-отстраненный и враждебно-подавляющий тип отношений между испытуемыми экспериментальной группы и их матерями.

Описанные выше особенности отношений в диаде «подросток-мать» способствуют повышению вероятности развития неврозоподобных и психосоматических расстройств и формирования отклоняющегося поведения испытуемых экспериментальной группы с последующей нарастающей социально-психологической дезадаптацией.

\section{Список литературы}

1. Вассерман Л. И., Горьковая, И. А., Ромицина Е. Е. Родители глазами подростка: Психол. диагностика в мед.-пед. практике. СПб.: Речь, 2004. 242 с.

\section{References}

1. Vasserman L. I., Gorkovaya I. A., Romitsina E. E. Roditeli glazami podrostka: Psikhol. diagnostika v med.-ped. praktike. St. Petersburg: Rech, 2004. 242 p.

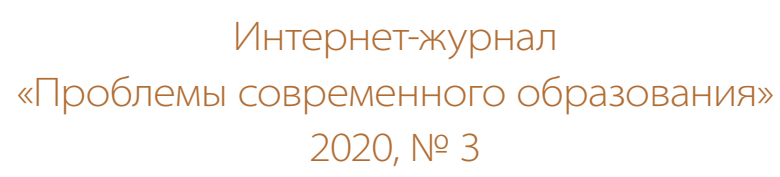

Статья поступила в редакцию 30.10.2019

The article was received on 30.10.2019 